\title{
A GEOGRAFIA ESCOLAR - E OS CONTEÚDOS DA GEOGRAFIA
}

\author{
Helena Copetti Callai ${ }^{61}$
}

\section{RESUMO}

Este texto discute o ensino da geografia e a didática, abordando os conteúdos. Parte-se da discussão da geografia escolar, do que se entende por Educação Geográfica e qual o seu papel escola. Em seguida está colocado o desafio para que seja possível fazer uma educação geográfica na escola, abordando a construção dos currículos e a escolha/definição dos conteúdos curriculares escolares. Estas questões são analisadas a partir dos estudos que acontecem no contexto da pesquisa em Didática e Ensino da Geografia que tem buscado na investigação cientifica a caracterização de como está o ensino-aprendizagem dessa disciplina, e de como são tratados os conhecimentos curriculares da mesma na escola.

Palavras chave: Educação geográfica, conteúdos curriculares, didática da geografia.

\begin{abstract}
This text discusses the education and learning of Geography considering that geographic science and the school geography, have specific characteristics, even so in its origin have the same one matrix. Discusses the school culture and of the school surroundings questioning the trend of didactic transposition. It approaches the paper of the school in the current world and of geography as curricular content, having established its paper of disciplines pertaining to school considering the elements that define it. It presents a reflection of the Geography that if its intend to teach considering the following aspects: what for, how, what, to whom. All the text is permeated by the idea of a geographic education, that serves so that the pupil learns to think space, meaning to understand the world considering the spatiality of the social phenomena, that if materialize in the space.
\end{abstract}

Key words: Education of Geography, learning, Geographic Education.

\section{RESUMEN}

Este texto discute la enseñanza de geografía y su didáctica través los contenidos. Su punto de despliegue es la geografía de la escuela; qué se entiende por Educación Geográfica y cual es su rol en la escuela. A seguir viene lo relacionado con la educación geográfica considerando la construcción de los currículos y la definición de contenidos curriculares escolares. Estas cuestiones se analizan desde los estudios que ocurren en el marco de las investigaciones en didáctica y enseñanza de geografía, el componente curricular; y cómo son trabajados tales conocimientos en la escuela.

Palabras clave: Educación geográfica, Contenidos curriculares, Didáctica de la geografía.

$61 \quad$ Actualmente se desempeña como docente en la UNIJUI y en la Universidad Regional del Noroeste del Estado do Rio Grande do Sul - IJUI- Rio Grande do Sul - Brasil. 


\section{INTRODUÇÃO}

O artigo aqui apresentado trata do ensino de geografia escolar e os conteúdos da Geografia. Aborda-se este tema, considerando que os conteúdos da disciplina são importantes, pois permitem estabelecer a especificidade da disciplina e, o diferencial dela em relação às demais áreas de conhecimento. O papel destes conteúdos, quer dizer, da disciplina escolar assume caráter significativo no contexto do currículo da escola básica e se desdobra nos objetivos e intenções de fazer o seu ensino. Este é o pano de fundo para nesse texto discutir o ensino da geografia e a didática, abordando os conteúdos. A discussão da geografia escolar e do que se entende por Educação Geográfica é importante para pensar qual o seu papel na escola. De mesma forma interessa o desafio para que seja possível fazer uma educação geográfica na escola, abordando a construção dos currículos e a escolha/ definição dos conteúdos curriculares escolares. Estas questões fazem parte do esforço de reflexão, sobre o significado da escola e da geografia (em particular), na formação dos jovens e crianças, a partir dos estudos que acontecem no contexto da pesquisa em Didática e Ensino da Geografia. Esta linha tem buscado na investigação cientifica a caracterização de como está o ensino-aprendizagem da disciplina, de como são tratados os conhecimentos curriculares da mesma na escola e de qual o papel dela na formação das crianças e jovens no mundo atual.

Refletir sobre escola, ensino e conteúdo curricular escolar reporta a reconhecer que a configuração do mundo atual na sociedade da informação apresenta novas formas de compreender os tempos e os espaços sob a globalização e requer, portanto novas formas de considerar o ensino da Geografia. Novas territorialidades emergem diante da complexidade em que se apresenta o mundo e, a Geografia se constitui numa ferramenta para entender este mundo. Neste sentido, para oportunizar que as pessoas compreendam a espacialidade em que vivem através da educação geográfica, se busca construir uma forma geográfica de pensar, que seja mais ampla, mais complexa, e que contribua para a formação dos sujeitos, para que estes realizem aprendizagens significativas e para que a geografia seja mais do que ilustração.

A geografia escolar se constitui como um componente do currículo, e, seu ensino, se caracteriza pela possibilidade de que os estudantes percebam a singularidade de suas vidas e, reconheçam a sua identidade e o seu pertencimento em um mundo que a homogeneidade apresentada pelos processos de globalização trata de tornar tudo igual. É, portanto uma matéria curricular que encaminha a compreender o mundo e, às pessoas a se entenderem como sujeitos neste mundo, reconhecendo a espacialidade dos fenômenos sociais. Portanto, através da leitura do espaço o importante é ler o mundo, o que significa compreender aquelas informações que estão no cotidiano das pessoas contextualizadas, compreendendo o significado das formas que desenham as paisagens.

Então, para ler o espaço há que se ter referenciais teóricos, instrumentos metodológicos, conhecer e compreender os conceitos básicos que permitem fazer esta leitura. Enfim, conhecer a ciência e a disciplina escolar para observar, analisar e interpretar a realidade. Outro aspecto fundamental é reconhecer o contexto da escola, o lugar em que ela está situada, o tipo de população, as formas de organização da mesma, o que permite explicitar as características dos estudantes que a freqüentam. E, ainda mais, é importante a clareza a respeito do papel da instituição escolar em seus ideais e na realidade prática para construir os instrumentos que permitam o acesso ao conhecimento que é a função especifica da escola. De acordo com Savater (2006) 
"el aprendizaje a través de la comunicación com los semejantes y de la transmisión deliberada de pautas, técnicas, valores y recuerdos es proceso necesario para llegar a adquirir la plena estatura humana. Para ser hombre no basta com nacer, sino que hay también que aprender.(2006:p.37).

Pode-se aprender de varias formas e em diversos lugares. No caso da escola, esta tem a função de, ao trabalhar com os conteúdos, realizar a sua tarefa de transmitir o que a humanidade produziu ao longo do tempo. Afirma Savater (2006) que,

"La enseñanza está ligada intrínsecamente al tiempo, como transfusión deliberada y socialmente necesaria de una memoria colectivamente elaborada, de una imaginación creadora compartida. No haya aprendizaje que no implique conciencia temporal y que no responda directa o indirectamente a ella, aunque los perfiles culturales de esa conciencia- cíclica, lineal, trascendente o inmanente, de máximo o mínimo alcance cronológico... - sean enormemente variados"( 2006: p. 40).

Diante disso se coloca reiteradamente a questão de como fazer o ensino da Geografia, (conteúdos específicos de uma matéria de ensino curricular e de uma ciência que se constitui como tal), para compreender a sociedade a partir da análise espacial. Os espaços são produzidos ao longo da história dos homens e estes espaços trazem em si as marcas das vidas passadas e as condições de vida atuais. De acordo com Santos (1994) nosso campo de estudo é o espaço territorial, o espaço humano. E, com apoio neste autor, pode-se afirmar que diante da fragmentação das disciplinas é preciso buscar as formas integradoras para entender o mundo em que se vive.

"Nesse processo de conhecimento, o espaço tem um papel privilegiado, uma vez que ele cristaliza os momentos anteriores e é o lugar de encontro entre esse passado e o futuro, mediante as relações sociais do presente que nele se realizam." (1994:p.122)

Este é o conteúdo da geografia e como tal, ao ser trabalhado na escola se desnuda a urgência de saber como fazer a transmissão de um conhecimento tão amplo e a necessária eleição/seleção de o que tratar. $\mathrm{Na}$ dúvida o professor assume a pretensão de ensinar tudo de todo o mundo e de todos os lugares o que não é razoável e nem possível. Neste contexto surge o livro didático como o disponibilizador/transmissor das informações geográficas necessários para a escola e para a formação dos jovens. O Livro - Didático, é, sem dúvida, uma possibilidade para democratizar o acesso ao conhecimento, e como tal uma poderosa ferramenta para a construção da cidadania. Resta saber como o professor o usa e como os alunos recebem as informações apresentadas e os conteúdos nele organizados, no dia a dia da sala de aula. Afinal, tradicionalmente, ensinar geografia é uma tarefa que tem sido apoiada enormemente pelo uso do Livro Didático para disponibilizar os conteúdos.

\section{A GEOGRAFIA ESCOLAR}

Falar da geografia escolar nos remete a toda a produção científica da Geografia ao longo de seus tempos. E, mais recentemente a discussão sobre educação geográfica leva a refletir sobre a geografia como campo do conhecimento e seu significado como conteúdo escolar. Por outro lado há que se considerar que o currículo e o conteúdo escolar são uma produção, e um conhecimento específicos, considerados a partir de várias vertentes e que se concretizam na fronteira do conhecimento disciplinar da ciência, na estrutura e cotidiano da escola e na vivência dos sujeitos envolvidos na escola. Portanto, a geografia escolar é um conhecimento diferente da geografia acadêmica, ela é pois, uma criação particular e original da escola, que responde às finalidades sociais que lhe são próprias. 
Diante disso, pode-se pensar num ensino de geografia que trate de um conhecimento disciplinar que não seja apenas do senso comum, mas que tenha bases científicas. E, que seja possível através dele conectar os alunos entre si e com o seu mundo, que seja um ensino que não se esgote nos exames e nas avaliações anuais. A idéia então, de uma educação geográfica, supõe tornar significativo o ensino da geografia. Isso vale para a geografia da escola básica e para a geografia da licenciatura, pois o professor que se habilita num curso de licenciatura tem em sua formação a carga dos conhecimentos pedagógicos, das didáticas e da própria ciência com que trabalha. O desafio é como fazer para estabelecer uma relação adequada entre os processos de ensino-aprendizagem curricular e como fazer para administrar uma tensão permanente entre a visão cientifica e a visão prática dos problemas educativos, da mesma forma que da ciência geográfica e a geografia escolar curricular.

Neste sentido, interessa caracterizar a Educação Geográfica e assim constatar que a geografia escolar se constrói como conteúdo escolar, na referência: 1. da academia a partir do que cabe à ciência na busca de explicações para problemas postos pela humanidade. Esta investigação apresenta resultados importantes para o entendimento do mundo em que vivemos. Caracteriza-se por procedimentos específicos de investigação com aportes teóricos e metodológicos e com linguagem também própria. 2- do contexto que apresenta marcas características dos lugares e como tal se constitui o trabalho com o currículo escolar. Este, demarcado pelos conteúdos curriculares escolares e pelas políticas publicas que o orientam. As pessoas envolvidas, os alunos, os professores e a comunidade escolar com um todo também demarcam esta característica.

A educação geográfica se caracteriza então, pela intenção de tornar significativos os conteúdos para a compreensão da espacialidade e, isso pode acontecer através da análise geográfica, que exige o desenvolvimento de raciocínios espaciais. Este é o caminho estabelecido para analisar, entender e buscar as explicações para o que acontece no mundo, para os problemas que a sociedade apresenta. No entanto, as pesquisas que estão sendo realizadas têm demonstrado que existem tensões que são manifestas no trabalho de ensinar a geografia. E, estas pesquisas têm auxiliado na compreensão da realidade da educação escolarizada. Os problemas se manifestam a partir das relações entre os vários sujeitos envolvidos no processo de ensinar e de aprender geografia. Estes podem ser caracterizados pelo seguinte: tensão entre os interesses do aluno e os do professor, entre a universidade e a escola, entre os diferentes espaços-recortes, na consideração do tempo e do espaço, dentre outros tantos. Enfim, realizar a educação geográfica exige mais do que simplesmente passar conteúdos.

\section{EDUCAÇÃO GEOGRÁFICA}

A Educação Geográfica é a possibilidade de tornar significativo o ensino de um componente curricular sempre presente na educação básica. Nesse sentido a importância de ensinar geografia, deve ser pela possibilidade que a disciplina traz em seu conteúdo que é discutir questões do mundo da vida. Para ir além de um simples ensinar, a educação geográfica considera importante conhecer o mundo e obter e organizar os conhecimentos para entender a lógica do que acontece. Isso remete a fazer um aprendizado significativo, a partir dos conteúdos da matéria de ensino escolar. Neste sentido com apoio em Savater (2006) pode-se argumentar que não é possível separar a educação da instrução porque não se pode educar sem instruir, nem vice versa. Diz ele:

“¿Cómo van a transmitirse valores morales o ciudadanos sin recurrir a informaciones históricas, sin dar cuenta de las leyes vigentes y del sistema de gobierno establecido, sin hablar de otras culturas 
e países (...) Y como puede instruirse a alguien en conocimientos científicos sin inculcarle respeto por valores tan humanos como la verdad a exactitud o 1 curiosidad?" (p. 47 e 48)

Muitas discussões são feitas sobre conteúdos curriculares, desenvolvimento de competências, de valores, acesso à informação, sistematização do conhecimento.

E o autor acima indicado ao discutir sobre os conteúdos escolares apresenta uma proposição que denomina de capacidades abertas e fechadas (a partir de John Passmore citado por ele). Assim se refere Savater:

"La enseñanza nos adiestra em ciertas capacidades que podemos denominar de "cerradas", algunas estrictamente funcionales- como andar, vestirse o lavarse- y otras más sofisticadas, como leer, escribir, realizar cálculos matemáticos, o manejar un ordenador.” (p. 48)

Essas aprendizagens são básicas e depois de aprendidas, diz o autor, o sujeito as sabe fazer, é só repetir e ir fazendo conforme as necessidades. As outras capacidades, as "abertas", por seu lado são de domínio gradual e de certo modo podem ser ampliadas para sempre, por toda a vida. Diz ele que algumas são universais e elementares, como falar ou pensar, outras podem ser optativas - saber pintar, escrever poesia. Estas nunca podem ser dominadas de modo perfeito. Sempre há o que aprender e não se pode dizer que não há nada mais a aprender, pois sempre existe algo mais e se pode ir mais adiante. Algumas destas aprendizagens podem exigir as fechadas como base, para fazer poesia é preciso ter aprendido a ler. Continuando na idéia do autor, ele afirma que outra diferença que existe é que o exercício repetido e rotineiro das capacidades cerradas as torna mais fáceis e mais seguras e podem ser feitas com mais tranqüilidade, no entanto quanto mais se avança nas capacidades abertas mais opções aparecem e surgem cada vez problemas mais complexos.

"Una vez dominadas, las capacidades cerradas pierden interés en sí mismas aunque siguen conservando toda su validez instrumental; por lo contrario, las capacidades abiertas se van haciendo más sugestivas aunque también más inciertas a medida que se progresa em su estudio.” (p.49)

As abertas exigem de nós cada vez mais consciência do que ainda falta enquanto que as fechadas podem ser feitas sem saber que se as sabe. A capacidade de aprender é uma capacidade aberta, a mais necessária e humana, e isso é a riqueza da educação e o desafio que a escola tem de enfrentar.

"Y cualquier plan de enseñanza bien diseñado há de considerar prioritário este saber que nunca acaba y que possibilita todos los demás, cerrados o abiertos, sean los inmediatamente útiles a corto plazo o sem los buscadores de uma excelência que nunca se da por satisfecha. La capacidad de aprender está hecha de muchas preguntas y de algumas respostas, de búsquedas personales y no de hallazgos institucionalmente decretados; de crítica y puesta en cuestión em lugar de em lugar de obediencia satisfecha com lo comumente establecido. En una palabra, de actividad permanente del alumno y nunca de aceptación pasiva de los conocimientos ya deglutidos por el maestro que éste deposita em la cabeça obsecuente."(p 49-50)

Estas capacidades são fundamentais para a vida humana, e na escola podem ser consideradas como referência para que o professor se instrumentalize a fim de tratar as temáticas que cabem em cada componente curricular. Para tanto é importante a clareza de que aprender é próprio do ser humano em se transformar em humano e que as tarefas são dispostas de modo a levar à aprendizagem. O professor ao conhecer a sua disciplina de ensino e a historia da mesma, assim como a história da ciência que lhe dá o nome, no caso a Geografia, tem os elementos para desenvolver a sua tarefa. 
Exige-se, pois do professor intimidade com a sua disciplina, e esta requer que ele tenha, perceba, compreenda e saiba operar com a dimensão técnica bem como a dimensão pedagógica da mesma. (Callai:1996)

Estudar e aprender Geografia fazendo a análise geográfica, através da verificação de como as ações da sociedade se concretizam/materializam no espaço nos encaminha a discutir a nossa realidade. Nunca é demais repetir pois esta é a centralidade da geografia ensinada. Os homens na sua vida em sociedade produzem a sua historia e esta se materializa no espaço. Entendemos então, que o espaço é também construído no cotidiano das nossas vidas. As informações sobre os lugares são fundamentais para fazer análise geográfica. E, esta nos permite observar, analisar e compreender esse espaço construído, como base física da sociedade, mas ao mesmo tempo como elemento (sujeito) ativo no estabelecimento de limites e possibilidades para a realização da vida social. Para fazer a análise geográfica é necessário desenvolver raciocínios espaciais. Através disso o estudante pode aprender a pensar e cria assim as condições de construir o seu conhecimento. Este resulta dos processos de contato com a informação e a organização mental dos dados e informações que the são disponibilizados. De um modo geral os dados recolhidos, e mesmo organizados e sistematizados podem servir ao uso que interessar a quem os manipula. No caso da produção da informação a partir destes dados já acontece um processo de produção que é politicamente estabelecido, quer dizer se escolhe qual a interpretação a fazer. De outra parte há na geografia todo o conjunto de conteúdos técnicos que são importantes para fazer a análise geográfica. Dizem respeito à grande parte da cartografia, mas também a outras especialidades da geografia - são aqueles aportes técnicos e instrumentais necessários, e que poderiam ser classificados nas capacidades fechadas acima referidas. Aliás, as capacidades abertas e as capacidades fechadas podem se constituir num interessante exercício para reflexão do significado dos conteúdos escolares da geografia. O que daquilo que se pretende ensinar na aula de geografia é base que sustenta o que pode ser aprendido e que permita abrir a possibilidade de aprender. É uma questão interessante, mas que aqui não será abordada com maior profundidade.

É importante ressaltar que a Geografia escolar trabalha com o ensino de um produto e uma das formas de apresentá-lo é através do Livro Didático. Este se utiliza da produção acadêmica da Geografia, (que se ocupa, de resolver os problemas postos pela humanidade a partir da pesquisa), e de outro lado se utiliza de inúmeras fontes que não necessariamente são cientificas, mas que advêm de variadas origens do cotidiano, de almanaques, de livros, da literatura, de noticias, de jornais, de revistas. E tem a referência às exigências postas a partir das políticas publicas que definem as diretrizes curriculares, e a normatização dos níveis de ensino. Nos livros - didáticos vários dados estão disponíveis, então o desafio é transformá-los em informações e constituir as bases para a construção do conhecimento. Nesse sentido é fundamental problematizar e contextualizar o conteúdo a ser trabalhado. Entram em ação as competências abertas que exigem a reflexão a interligação das informações e as explicações de sua origem de seu contexto e da mesma forma os motivos que levam a este tipo de interpretação.

\section{OS CONTEÚDOS DA GEOGRAFIA ESCOLAR}

O currículo e o conteúdo escolar são uma produção e um conhecimento específico, considerado a partir de varias vertentes e que se concretiza na fronteira do conhecimento disciplinar da ciência, na estrutura e cotidiano da escola e na vivência dos sujeitos envolvidos na escola. Portanto, considera-se a geografia escolar como um conhecimento diferente da geografia acadêmica. A geografia 
escolar é uma criação particular e original da escola, que responde às finalidades sociais que lhe são próprias. Se os currículos nunca se apresentam de modo homogêneo em todo o território nacional, nem o ensino dos conteúdos da Geografia será da mesma maneira ensinado. Aqueles (currículos) necessariamente se revestem das características da escola e do lugar em que se inserem e da mesma forma os conteúdos disciplinares assumem demarcação especifica.

Diante disso, pode-se buscar um ensino de geografia que trate de um conhecimento disciplinar que não seja apenas do senso comum, mas que tenha bases científicas. E que seja possível através dele conectar os alunos entre si e com o seu mundo. Isso vale para a geografia da escola básica e para a geografia da licenciatura que forma os professores para aquela. O professor que se habilita num curso de licenciatura tem em sua formação a carga dos conhecimentos pedagógicos, das didáticas e da própria ciência com que trabalha. A geografia escolar é, portanto aquela que traz em si a informação (conteúdo especifico) e a dimensão pedagógica que carrega em si própria. (Callai: 2010a e 2010b.)

Na escola básica a dificuldade apresentada por vários fatores (que não cabem ser discutidos aqui) leva a que os professores procurem simplificar o seu trabalho de modo a buscarem a pretendida qualidade necessária para fazer o ensino. E, o livro didático é uma ferramenta poderosa para tanto, por tornar acessível o conteúdo através das informações que apresenta e do conjunto de atividades e orientações que permite ao professor desenvolver suas aulas. No entanto, é importante verificar como ocorre a interligação entre estes livros (pelo que está contido neles) e os objetivos que permeiam o ensino, fazendo com que retorne então a questão do que seja a ciência Geografia, do que seja a disciplina escolar e como são definidos os conteúdos escolarizados. Na tentativa de superar a idéia de transposição didática, (de que o conteúdo da ciência vai sendo reorganizado e simplificado até chegar ao aluno e que o livro seja um dos instrumentos desta "passagem"), busca-se a interligação com o contexto. Proporciona-se então a interlocução entre os sujeitos envolvidos no processo de ensino e aprendizagem, reafirmando as orientações da ciência geográfica na mesma medida em que se constitui a disciplina escolar situada nos contextos de espaço e tempo em que acontece. E, neste entendimento exige-se muito mais do que simplesmente trabalhar determinados conteúdos, pois diz da necessidade de compreender que a ciência e a disciplina escolar se constroem de forma diferente e que uma não é mera repetição da outra de modo a simplificar o conteúdo. Em resumo, está claro que o que acontece com os conteúdos escolares não se reduz a simples passagem seqüencial da ciência para o que é ensinado na universidade e para os livros didáticos e para o que o professor ensina, e que o aluno aprende.

Retomando a questão de que os currículos escolarizados são definidos de modo interessado reafirma-se a idéia de que o professor deve ter clareza das questões para que possa ele próprio trabalhar do modo que seja mais conveniente para que seus alunos aprendam aquilo que é o especifico da escola e da geografia escolar. No caso do uso do livro didático é importante ter claro que um texto didático está produzido e se apresenta pronto e acabado, nesse sentido cabe ao professor fazer os questionamentos que permitam reconhecer a instabilidade e superação do conhecimento. Ao questionar é possível abrir caminho para desvendar o novo, para descobrir além do que está posto. Será possível um texto didático estar aberto para que o conteúdo do mesmo possa ser problematizado e contextualizado?

Pode-se acrescentar o questionamento de como está apresentado este conteúdo, se existe uma organização seqüencial que permita ao professor desenvolver as suas aulas É importante, por outro 
lado, indagar se o texto apresenta uma "seqüência didática" ou é o professor que deve realizar isso. A seqüência didática tem como expectativa a realização de uma aprendizagem significativa e que permita que o aluno construa um pensamento autônomo sendo ele próprio autor de sua aprendizagem, sendo capaz de articular diferentes conteúdos na busca de entendimento da realidade em que vive. Observando os textos didáticos, pode-se verificar se o LD apresenta essa possibilidade de realizar a seqüência didática, fazendo ou propondo a organização dos conteúdos. Mas de qualquer forma é adequado verificar se o texto e o conjunto da obra didática permitem a abertura para o professor realizar essa estratégia didática possibilitando a construção do conhecimento de parte do aluno.

No ensino e aprendizagem (de geografia) é importante que o professor tenha o controle do processo do ensino que está fazendo, pois a ele dar a direção uma vez que é sua a função da autoridade no ensinar. A ele cabe oportunizar a passagem do conhecimento produzido pela humanidade para que os alunos o aprendam. Ao professor se atribui também, fazer a condução necessária para que os alunos conheçam, isto é, que sejam informados e que estas informações possam se tornar um conhecimento significativo para as suas vidas. Estabelecer uma sequência didática pode ser simplesmente uma estratégia para encaminhar o ensino. Mas se torna mais que isso ao exigir que o professor saiba aquilo que vai ensinar e que conheça para além daquilo que vai ser trabalhado, isto é que conheça a sua ciência, que compreenda o significado daqueles conteúdos no contexto da sua disciplina escolar.

De parte do aluno a organização que o professor proporciona ao fazer o ensino pode ser o caminho que lhe permita aprender mais e melhor. Questiona-se então se é possível perceber num livro didático através dos textos, das atividades apresentadas, das orientações fornecidas ao professor para o uso do livro, qual a proposição para o encaminhamento das aulas. São estas as condições para que se efetive um ensino consistente e com a abordagem dos temas curriculares de modo que sejam significativos para os alunos e, a partir daí surge então, outro problema que é demarcado pelos interesses envolvidos decorrentes da postura teórica dos referenciais adotados, dizendo respeito à ciência, a disciplina escolar, aos aspectos pedagógicos do ensino, e a necessidade pragmática de formação na escola e da instrução considerando-se os conteúdos.

Avançando nesta reflexão caracteriza-se a difícil tarefa de como compreender e administrar uma tensão permanente entre a visão cientifica e a visão pratica dos problemas educativos. Diante de inúmeras injunções e de possíveis alternativas pode-se trazer a tona a possibilidade de reflexão sobre o fazer do estudante e a construção de uma pratica escolar, acadêmica e centrada na pesquisa. No caso do aluno de cursos de licenciatura-formação de professores, depreende-se que é preciso conhecer e aprender a fazer para saber ensinar. E uma alternativa que tem sido usada comumente diz respeito a tarefa de escrever e reescrever sobre a sua pratica, considerando os conteúdos específicos da sua disciplina escolar, construindo um texto que tem significado de uma reflexão sobre a sua pratica. Escrever sobre o que faz pode levar o professor e o aluno da graduação a tomar consciência do que é o seu trabalho e a aprender a definir os conteúdos com que vai trabalhar. Isso tornaria possível ter o Livro Didático apenas como um auxiliar na condução do trabalho, muito embora este na maior parte das vezes se constitui no definidor dos conteúdos que serão abordados.

Não há como fugir de uma discussão (necessária) a este respeito, uma vez que o livro didático "formatado" a partir das exigências postas pelas políticas públicas passa a ser ele próprio o condutor/orientador do que deve ser feito em sala de aula. O desafio é como proceder diante da situação 
e, se descortina então, outra questão importante a ser discutida, pois o LD existe e como tal é o material que torna acessível o conteúdo a ser trabalhado na escola. Quando bem organizados e de acordo com as referencias da ciência e da geografia escolar o seu uso pode se tornar adequado ao mais exigente professor.

Para desenvolver ações que visem uma aprendizagem significativa e que para isso articulem conteúdos e estratégias diversas, é adequado considerar os tipos de conteúdo trabalhados, que podem ser classificados em factuais, procedimentais, atitudinais e conceituais. Vários autores têm trabalhado com esta divisão e nos documentos oficiais que orientam a educação escolarizada, muitas vezes aparecem como competências a serem desenvolvidas pelos estudantes como forma de o ensino ser efetivado. Sem muito aprofundamento, mas que pode demonstrar o seu significado estes conteúdos podem ser caracterizados como:

Conteúdos factuais- são aqueles de fatos singulares, que abordam fenômenos concretos. São os dados que disponibilizados podem ter usos variados. Esses usos podem ser de o aluno decorar o dado, e através da memorização ao repetir criar associações capazes de auxiliar na "guarda dos dados" em especial para dar conta da realização da averiguação da aprendizagem. São aquelas informações que podem advir dos noticiários, dos livros, dos mapas e sendo corriqueiras são também consideradas do aporte de conteúdos específicos da disciplina. No caso da Geografia dizem respeito as informações sobre aspectos físicos da natureza, da organização do espaço, de população, de desenvolvimento econômico social, de classificação regional, de hierarquias urbanas e de países, por exemplo.

Conteúdos procedimentais - significa construir a capacidade de fazer e de saber fazer. Isso permite que o estudante saiba adotar os procedimentos adequados para realização de determinada tarefa, significa que ele aprendeu a fazer, que ele sabe fazer. Ao ter o contato com vários dados e informações ele sabe trabalhar, fazer as articulações, confrontar as idéias rearranjar a sua aprendizagem, o seu conhecimento elevando-o a outro patamar de maior complexidade. Realizar a aprendizagem desses conteúdos procedimentais requer a mediação do professor, pois sempre está suposta a discussão, o conflito entre as varias formas de ver o tema. Isso pode ocorrer no contexto de um trabalho de grupo, em observações concretas da realidade e também na interação com o texto. No trabalho com mapas, com gráficos, tabelas, com trabalhos de campo - observações, entrevistas, com a orientação espacial, pode - se verificar a capacidade do aluno de trabalhar com variadas fontes, e conseguir ter os instrumentos para dar conta de fazer o estudo especifico. Num ensino que preconiza a autonomia do sujeito esse tipo de conteúdo é básico e intransferível. Cabe ao professor fazer a mediação - coordenando as ações para que o estudante avance. Mas para isso o professor precisa ele saber e ter intimidade com o conteúdo, para que possa entusiasmar o aluno a querer aprender e ter interesse em compreender o que lhe está sendo passado.

Conteúdos atitudinais: são aqueles que tratam de valores, de atitudes, de comportamentos. Está fortemente assentado nas relações entre os diversos grupos e indivíduos da escola, e dessa maneira envolve o aspecto afetivo e emocional. Podem dizer das convicções cidadãs dos sujeitos, do respeito à diferença, da valorização do outro. Também tem a ver com construção da identidade e do pertencimento das pessoas, de modo que sejam capazes de respeitar e valorizar o lugar em que vivem. Muitas vezes estes conteúdos nas aulas de Geografia são pretensiosamente "passados" para os alunos de modo a que desenvolvam o nacionalismo e o patriotismo. De forma pretensiosa porque não é passando informação ou dando ordens que se incorporam conteúdos atitudinais. E, muitas vezes 
tem grande peso ideológico o que faz com que o sentido seja de "obedecer" sem questionar, porque alguém considera que isso seja o ideal. Pode ser um equivoco na medida em que a educação abre as possibilidades de entender o mundo e não determina um caminho só. De outra parte pode ser considerada pretensão pelo fato de que nas escolas são destinadas à área dos Estudos Sociais, onde se inscreve a Geografia, as ações que dizem respeito ao patriotismo, à comemoração dos grandes feitos, as campanhas de conscientização e as bandeiras de/para salvação do mundo.

Valores, comportamentos e atitudes são resultado do modo como se encara o mundo, e como tal precisam de outros conhecimentos que podem dar a sustentação para a construção destes conteúdos pelos alunos. Aqui, novamente o papel do professor é importante, mas da família, sem duvida é muito grande.

Conteúdos conceituais- são aqueles conteúdos que o estudante pode além de reproduzir e de repetir a definição do conteúdo trabalhado, usá-lo como instrumento para interpretar, para avançar na compreensão da realidade em que vive ou simplesmente da temática que está sendo estudada. A idéia de construção de conceitos supõe a complexificação cada vez maior do mesmo no decorrer das aprendizagens. Supõem ser capaz de problematizar e de contextualizar o que está sendo estudado e, situando a temática num âmbito maior. Os conteúdos conceituais passam a ser ferramentas que auxiliam na interpretação dos demais tipos de conteúdos.

$\mathrm{Na}$ Geografia há um conjunto de conceitos que formam a base dos conteúdos específicos, e que se constituem nas ferramentas para fazer a análise geográfica. Um dos conceitos importantes para trabalhar a Geografia é o de Lugar. Este é um conceito que oportuniza a realização da análise geográfica ao ser trabalhado na perspectiva da escala de análise. Neste entendimento o conceito de lugar interessa por entendermos que o mesmo se expressa como a possibilidade de entender o mundo.

\section{O CONCEITO DE LUGAR E O ESTUDO DA GEOGRAFIA ESCOLAR}

Trabalhando na perspectiva de "estudar o lugar para compreender o mundo" (Callai, 2008) o conceito de lugar é importante no estudo de geografia. O Lugar é o território apropriado, que demonstra em si através de rugosidades, a história das vidas que ali foram e estão sendo vividas. Dessa forma sendo resultado, também gera necessidades, exige definições, impõe limites e apresenta possibilidades. Nesse sentido, o espaço adquire/incorpora um poder, que é político e que pode dar os contornos para a ação humana, podendo-se inclusive falar de poder do espaço (Callai: 1986). Então, todos são responsáveis pela construção do espaço, todos os homens são capazes de deixar as suas marcas.

Entendendo o lugar a partir desse conceito de espaço, pode - se reconhecer as capacidades decorrentes dos princípios que exigem a participação dos vários atores sociais nos processos de construção da vida, produzindo um espaço enquanto fazem a sua história. O conhecimento das potencialidades do lugar e das capacidades de ação das pessoas que ali vivem são condições fundamentais para o exercício de fazer do lugar aquilo que interesse a quem vive nele. Reconhecer que existem potencialidades no lugar e que as pessoas tem capacidades, muitas vezes para além do que lhes é exigido e até permitido, já é um passo na busca de construção de um lugar solidário para a vida de todos que ali vivem, mas acima de tudo é muito importante ter a compreensão do que está acontecendo, seja no lugar, seja no mundo. Essa busca gera necessariamente um processo de aprendizagem, com significado, para a vida particularizada de cada um e a vida, do/no conjunto da sociedade. Quer dizer, não é a escola simplesmente cumprindo conteúdos curriculares, mas desenvolvendo atividades 
que tornem o sujeito capaz de conhecer para mudar. E, principalmente encontrar os caminhos para como mudar, pois estamos vivendo num mundo que precisa ser conhecido e compreendido, não pelo lugar em si, mas no conjunto em que cada lugar se contextualiza. No dizer de Milton Santos, 1994:

"Para ter eficácia, o processo de aprendizagem deve, em primeiro lugar, partir da consciência da época em que vivemos. Isto significa saber que o mundo é e como ele se define e funciona, de modo a reconhecer o lugar de cada país no conjunto do planeta e o de cada pessoa no conjunto da sociedade humana. É desse modo que se podem formar cidadão conscientes, capazes de atuar no presente e de ajudar a construir o futuro" (p.121)

A partir dessa compreensão, o desafio é o de cada um ser protagonista na/da construção de seu espaço, da sua história e da sua sociedade. Este papel de serem autores de suas próprias vidas se coloca como a alternativa para fazer frente ao processo de globalização que se impõe sobre todos os lugares de todo o mundo. A capacidade de perceber como é o lugar, qual a sua conexão com o mundo, quais as possibilidades de fazer frente às injunções externas passa a ser fundamental para fazer as escolhas e definir as formas de organização e planejamento das interferências no desenvolvimento. O que é esse lugar e qual a "força do lugar" (Santos: 1996) pode ser o desafio, para professores e estudantes de todos os níveis, se preocuparem com a investigação, conhecimento, e compreensão do lugar. No lugar é que se pode ter a real dimensão do universal, pois é no lugar que conhecemos, vivemos, pisamos que podemos senti-lo, e vivenciar tudo que nos afeta.

Essas considerações dizem respeito ao estudo do lugar, de forma empírica, observando, reconhecendo e compreendendo como ele se apresenta. Mas o empírico é apenas uma parte que permite trazer as informações e diante delas é preciso fazer as reflexões que permitem as abstrações necessárias para compreender o mundo. Qual o papel dos conteúdos, então? A análise geográfica exige o suporte teórico que tem em si um conjunto de conceitos e, para trabalhar com estes exige-se a clareza do seu significado e do que possam representar no contexto dos conteúdos tratados. Estes têm um papel importante no contexto da aprendizagem, pois é o conjunto de idéias de informações de competências e habilidades que se quer ver mantidas. Diz Savater que "En una palabra, la educación es ante todo transmisión de algo y solo se transmite aquello que quien há de transmitirlo considera digno de ser conservado". (Savater, 148). Mas mesmo assim não há homogeneidade e nem sentido único na educação. A escola mesmo trabalhando com a cultura dominante não a tem como exclusiva. Pensando na proposição de estudar o lugar para compreender o mundo, ao ter a escala de análise como instrumento metodológico para a leitura do espaço, as singularidades são explicadas e entendidas no contraponto da universalidade. Savater afirma que, por mais oficial que seja a pretensão pedagógica,

"siempre resulta cierto lo que apunta Hubert Hannoun em Comprendre léducation:" La escuela no transmite exclusivamente la cultura dominante,sino más bien El conjunto de culturas em conflicto em el grupo del que nace"(149)

Uma vez que os conteúdos são sempre estabelecidos a partir de interesses, o mínimo que se pode querer é que o professor tenha claro a quem está servindo, a que motivações ele responde com o conteúdo que seleciona para as suas aulas de geografia. Para além dos conteúdos há um conjunto de capacidades (abertas e fechadas de acordo com a proposição de Savater), que se deve reconhecer no estudo da Geografia, expresso como um conjunto de habilidades básicas para observar, descrever, analisar os elementos espaciais e também fazer a sua representação. Estas uma vez aprendidas podem ser a base para a construção do conhecimento a partir da elaboração e organização das informações que são oferecidas na escola. 
O LD como suporte ao acesso à informação é neste contexto um poderoso instrumento para tornar acessível ao aluno o conhecimento produzido. O risco é aceitar como se este seja o único e o "correto". A capacidade "aberta" de ir avançando no conhecimento supõe que seja exercida a critica, que sejam criadas condições para fazer perguntas, para questionar as verdades trazidas pelo texto didático. A instrução e a formação caminham juntas, portanto os conteúdos são fundamentais para ampliar o modo de ver o mundo, para se reconhecer neste mundo como um sujeito. A escolha de que conteúdos devem ser tratados na sala de aula depende, portanto dos interesses que existem na sociedade atual. E os textos escolares respeitam este interesse através do cumprimento das políticas publicas especificas e, inseridos no contexto geral destas. Se o professor não consegue ser o condutor de sua aula - seja por falta de conhecimento especifico da matéria, seja por falta de outras condições alguém externo a ele, ocupa o seu lugar.

Enfim, não há maiores problemas em fazer uso do texto do Livro escolar, pois ele muitas vezes é o único livro a que o aluno tem acesso e, portanto indispensável. O que precisa é a clareza dos aportes teóricos da disciplina escolar, dos aspectos pedagógicos que dizem respeito ao ensinar. Mas, principalmente conseguir fazer as escolhas e, estas podem e, devem ser realizadas a partir do conhecimento de para que serve a disciplina escolar, de qual é o significado da geografia escolar no contexto da escolarização formal, quais os objetivos que lhe cabem e, diante disso verificando como é a melhor e mais adequada forma de trabalhar os conteúdos.

\section{BIBLIOGRAFIA}

Callai, H. (1986). Espaço de poder ou o poder do espaço. Revista Contexto e Educação, (3).

Callai, H. (1996). A formação do profissional em Geografia. Ijui - RS Editora UNIJUI.

Callai, H. (2002). Estudar o lugar para compreender o mundo. In Geografia - práticas e textualizações no cotidiano. PA: Ed. Mediação.

Callai, H. (2010a). Didáctica y geografia: La investigación cualitativa em la didáctica de la geografia. In Ávila Ruiz, R. M.; Rivero Gracía, M. P.; Dominguez Sanz, P. L. (coords.). Metodologia de investigación en Didáctica de las Ciências Sociales (159-166). Zaragoza: Institución Fernando E1 Católico.

Callai, H. (2010b). A educação geográfica na formação docente: convergências e tensões. In Dalbén, R.; Diniz, J.; Leal, L. e Santos, L. Convergências e tensões no campo da formação e do trabalho docentes: ensino de geografia (412-433). BH: Autentica.

Santos, M. (1994). Técnica, espaço e tempo-globalização e meio técnico cientifico informacional. SP: Ed. Hucitec.

Santos, M. (1996). A natureza do espaço- emoção e razão. SP: Ed. Hucitec.

Savater, F. (2006). El valor de educar. Barcelona: Ed. Ariel.

Artículo recibido 21 - 09 - 10. Aprobado $26-11-10$. 